\title{
Sri Dalada Maligawa - 3D-Scanning and Documentation of the Temple of the Sacred Tooth Relic at Kandy, Sri Lanka
}

\author{
M. Rahrig ${ }^{\text {a }}$, A. Luib $^{\text {a }}$ \\ ${ }^{a}$ KDWT, Centre for Heritage Conservation Studies and Technologies, Bamberg University, Germany \\ (max.rahrig, anna.luib)@uni-bamberg.de
}

\section{Commission II}

KEY WORDS: Digitizing World Heritage Sites, 3D-Documentation, Heritage at Risk, Digital Archive, Transfer of Knowledge

\begin{abstract}
:
Sri Dalada Maligawa - the Temple of the Sacred Tooth Relic - is one of the most important pilgrim sites in Buddhist culture. It is the main part of the UNESCO World Heritage Site Sacred City of Kandy. Since the end of the $17^{\text {th }}$ century the temple has been keeping the sacred tooth of the Buddha. Until now an accurate documentation of the temple with all its rich decorations is missing. The Temple is built in an area vulnerable to environmental factors like earthquakes or monsoon rains and was the target of terrorist attacks. To help preserving this important cultural heritage a research project was carried out. Main part of the project was a 3Ddocumentation of the entire temple by using Terrestrial-Laser-Scanning (TLS) and the creating of CAD-Plans. In addition to the documentation of the architecture several details were taken in high resolution by Structured-Light-Scanning (SLS). All data will be part of the digital archive of the temple and were used as a base for a general site monitoring, especially to observe cracks. Next to the mere documentation a transfer of knowledge was another aim of the project. In future most of the analysis of the scan data can be done by local specialists.
\end{abstract}

\section{THE SITE}

Sri Dalada Maligawa (Fig. 1), the Temple of the Sacred Tooth Relic, is one of the most important pilgrim sites in Buddhist culture. The temple and its surrounding buildings form the Chorus of the UNESCO World Heritage Site Sacred City of Kandy in the central highlands of Sri Lanka. On the north side of the Kandy Lake next to the city centre of Kandy there is an area which concentrates on Buddhist and Hinduist temples, shrines and stupas. The British colonialists also built up a catholic church, St. Paul's, next to the temple site. On the east end of the area the former King's Palace with the Temple of the Sacred Tooth Relic is situated on top of a terrace 4 meters above the surrounding area. At the end of the $17^{\text {th }}$ century when the Sinhalese kings ruled their country from Kandy city again, they built up a temple to store the most important Buddhist Relic of Sri Lanka: the sacred tooth of the Buddha. This relic was also a symbol of the royal power (De Silva, 1985).

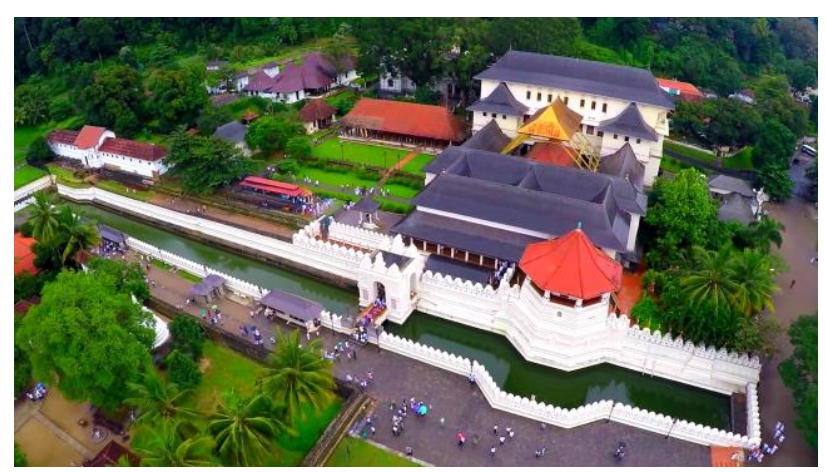

Fig. 1. The temple complex at Kandy

\footnotetext{
* Corresponding author
}

During the centuries several structural changes on the area took place: Today the ancient royal buildings like King's Palace, Queen's Palace, Audience Hall and Royal Bathing Place are grouped in a wide, open park around the temple buildings (Fig. 1 ). These are part of a grown structure with ancient buildings from the $17^{\text {th }} / 18^{\text {th }}$ century like the Pattirippuwa/Octagonal tower now containing an important library of historical Buddhist Sanskrit scripts. Besides there are younger parts like the new shrine room and museum from 1936 at the east end of the complex. In the centre of the site there is an open courtyard where the sanctum, a two-storied shrine preserving the Sacred Tooth Relic, is located and now additionally covered with a gilded modern roof (De Silva, 1994).

All over the temple area there are rich and filigree decorations in different materials like wall paintings, well carved woods, ornamented stones and gilded surfaces. The Audience Hall from the $17^{\text {th }} / 18^{\text {th }}$ century for example is preserved as an open hall founded on a profiled bed stone. The roof is based on a construction with 64 wooden pillars. Each pillar and most of the horizontal beams are decorated with complex carved floral ornaments. In front of each entrance to the temple and to most of the adjacent buildings moonstones are situated (De Silva, 1985).

Moonstones are traditional doorsteps with a central meaning in the Buddhist culture. During the period of the Kandyan Kingdom they are mostly triangle shaped stones with a round lotus in the centre surrounded by floral ranks (Seneviratna, 1987). The lotus allegorizes the nirvana surrounded by material desires and lusts. By stepping over a moonstone into the temple the believer will lose all material desires and lusts analog to the passage into the nirvana. At Sri Dalada Maligawa more than 15 ancient moonstones are preserved (IBM, 2015).

The shrine itself is the most and richest decorated part of the whole site. It is situated on a profiled bed stone in the centre of 
the temples courtyard. There are wall paintings on each side of the shrine showing ornaments as well as figures and special animals. The ground floor is surrounded by a veranda. Stone pillars decorated with carvings and paintings carry a wooden canopy. It is richly painted and very colourful, the ceiling beams frame picture fields telling the story how the Sacred Tooth reaches Sri Lanka and becomes a royal insignia (De Silva, 1985). The main side of the Shrine facing the west to the drum beating corridor contains a portal with silver covered doors and a coloured stone door frame (Fig. 2). The drum beating corridor itself guides the visitors directly to the shrine after entering the temple building through the main entrance.

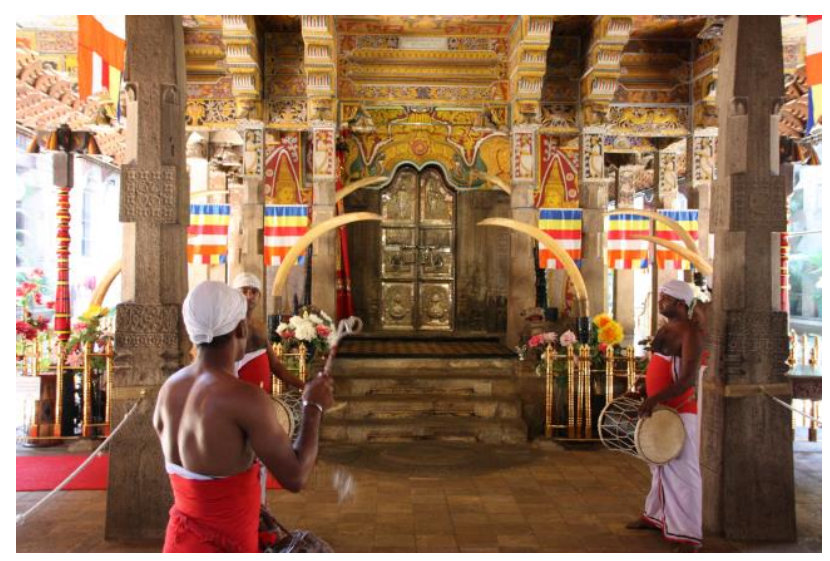

Fig. 2. Drum beating corridor and main side of the shrine

\section{HERITAGE AT RISK}

Because of its meaning as the most important Buddhist site in Sri Lanka several thousand pilgrims from all over the world visit the Sri Dalada Maligawa each day to pray or to sacrifice in front of the sacred tooth. It is also one of the most popular tourist magnets of the island. Every guided bus tour through the country has to include a sight-seeing tour in Kandy. Furthermore, individual tourists and back packers usually make an intermediate stop during their travels through the central highlands and tea plantations.

This very high number of visitors means an enormous burden and stress for the historical structures. Continuous passing over, pushing and sliding along the historical surfaces causes damages and loss by deterioration.

Because of its religious, cultural and touristic importance the temple was a main target of terrorist attacks for several times, most recently in January 1998, when the Tamil Tigers (LTTE) blew up the main entrance. During the attack 17 visitors lost their lives and the historical buildings took enormous damage because of the explosion and the corresponding vibrations. The detonation was extremely powerful and the surrounding temples and shrines in the western area were also affected. Even $150 \mathrm{~m}$ away, at St. Paul's Church, the historic stained glass windows were damaged. The detonation destroyed the whole entrance with its ancient elephant reliefs and a famous ancient moonstone. In addition the foundations and upper walls at the main façade of Sri Dalada Maligawa were thoroughly damaged, especially the Pattirippuwa/octagonal tower (Coningham/ Lewer, 1999).

During the reconstruction work most of the building structures were repaired, but there has been no site monitoring or static assessment since the work was finished. Until today there are many deep and complex cracks visible in the masonry. Considering its location in an area vulnerable to environmental and climatic factors like earthquakes or monsoon rains in combination with the existing structural damages after the attack the Sri Dalada Maligawa is a heritage at risk!

Until nowadays repairing, modifications and structural strengthening of damaged parts is mainly focusing on the religious and spiritual usability of the buildings or objects. For a fast recovering in their use for rituals and customs normally it leads to replacement and reconstruction. The irretrievable loss of the material heritage, resulting from that processes, is a problem which is realised by the responsible very slowly. So there is a lack of experience in handling the rising heritage consciousness and they really need support about the practical and conceptual care and maintenance of their cultural heritage. This is highly important to preserve and save the world heritage site for future generations.

\section{PROJECT REQUIREMENTS}

Since the terror attack particularly the local community, but also the general public, has been worried about their holy place. Nonetheless, a site monitoring or a general documentation of the status quo was missing until the project started. The temples administration did not have any architectural drawings which are absolutely indispensable as a basis for ongoing and future construction works or for the design of a new visitor guidance system or even an emergency escape route map.

The Special Project and Media Bureau of the temple is operating on a high technical level disposing of 35 employees and support for special projects. They had their own podcast video channel and realize live shows, documentations, interviews and reports all by their own.

In collaboration with the Media Bureau and three SMEs from Sri Lanka and Germany a research project for a first documentation of the temple was carried out in October 2015, founded by the Cultural Preservation Programme of the German Federal Foreign Office. The project duration was agreed to be about one year starting with six weeks of fieldwork. This limited time period was filled with a lot of measures and corresponding activities. The entire temple complex with all of its buildings and numerous details had to be documented in 3D and in a high resolution. The projects aim was to use the data for generating CAD-drawings, a basis for site monitoring of damaged areas as well as 3D-animations and other visualisations (Gonizzi Barsanti et al., 2013) for facility management and emergency escape route maps. Therefore, it was necessary for the documentation to be done using Terrestrial-Laser-Scanning (TLS) on the overall area and Structured-Light-Scanning (SLS) for details.

Another major requirement was the possibility to have locals trained in processing and analysing the data and in heritage preservation to give a fast support to the temple administration. Due to the short project duration it was impossible to process all data and generate all required CAD-drawings. For a completion of the work later a transfer of knowledge is useful too. The Sri Lankan colleagues were trained in all relevant processes and in handling of the - to them - new 3Dtechnologies. In future most of the analysis and processing of the scan data can be carried out by these local specialists.

\section{FIELDWORK}

The scanning campaign was done within six weeks in November and December 2015. During this time all work was carried out by a team of four to five people, two Sri Lankan and two or three German specialists. The fieldwork was divided into four steps: First of all a measuring of fixed control points was 
required, followed by the Terrestrial-Laser-Scanning of the whole site, afterwards Structured-Light-Scanning of important details was executed and in the end an introduction into the post-processing of the data was given to the Sri Lankan colleagues.

\subsection{Measuring of control points}

As a basic surveying for orientation and registration of the scan data several fixed control points spread over the temple area were marked at the ground and measured with a total station (Wiedemann, 2004). The georeferencing of the measurements is attempted, but no GPS GNSS rover was available, but existing measuring points located by the local surveying office were used. Here, in particular, fixed points in the street between Media Department, Temple and World Buddhist Museum. In the future these points can be used to co-register additional scans with the collected data. For the site monitoring the fixed points can be used for the correct orientation of new scans from already measured areas. The coordinates provided by the surveying office were not available during the project duration, so the measurements were made in a local reference system. As soon as the necessary data have been transmitted, the georeferencing can be made up.

\subsection{Documentation of the building complex}

A complete documentation of all buildings and the surrounding park was intended. Because of the short time span available and the tremendous and extensive requirements on the documentation the scanning device had to be chosen carefully (Grussenmeyer et al., 2016). The use of an often successfully used Faro Focus 3D was discussed especially because of its low weight, small packing size and its easy handling. This device is currently often used for a fast documentation of building complexes. But it is impossible to register or to check the completeness of single scans directly in the workflow on site without losing much time. Its use during visitor traffic was impossible due to the covering of important parts and tie points by tourists.

Alternatively it could have been possible to generate a DigitalSurface-Model (DSM) of the temple site using Image-Based Modelling Techniques in combination with a unmanned aerial vehicle (UAV) (Stylianidis et al., 2016). This could provide a fast and good basis for developing visitor guide maps and emergency escape route maps. However a complete documentation of all areas including the inner building parts in a resolution up to $3 \mathrm{~mm}$ exceeded the limits of this technique. In addition, data collection had to be carried out during full visitor traffic. With a few thousand visitors per day a feature-based 3D reconstruction is impossible because of too many movements and deviations in the photo series.

A Riegl VZ 400 (Fig. 3) was chosen because of the difficult determining factors of the project. One of the great advantages of this device is that it can be used in a standalone mode without any external hardware; however, in this case the registration of the single scans must be processed later in the office. Experience has shown that the separation of the measuring and registering of multiple scan positions is not very efficient, because the workflow can be very abstract and difficult to understand for untrained or inexperienced people. That is one reason why the scanner is used in combination with a laptop and the software RiSCAN PRO for controlling the device on site. There are additional advantages in using this workflow: The single scans can be checked for completeness and accuracy directly in the field. As the measurements had to be done during daytime at regular visitor traffic, you always have to check if all important areas are measured or if a remeasurement is necessary because visitors covered some parts. Another advantage is that the correct capturing of reflector marks, which are used to register scan positions and the standard deviation of registered scans can also be checked directly. A maximum deviation for all scans of about approximately $3 \mathrm{~mm}$ is guaranteed.

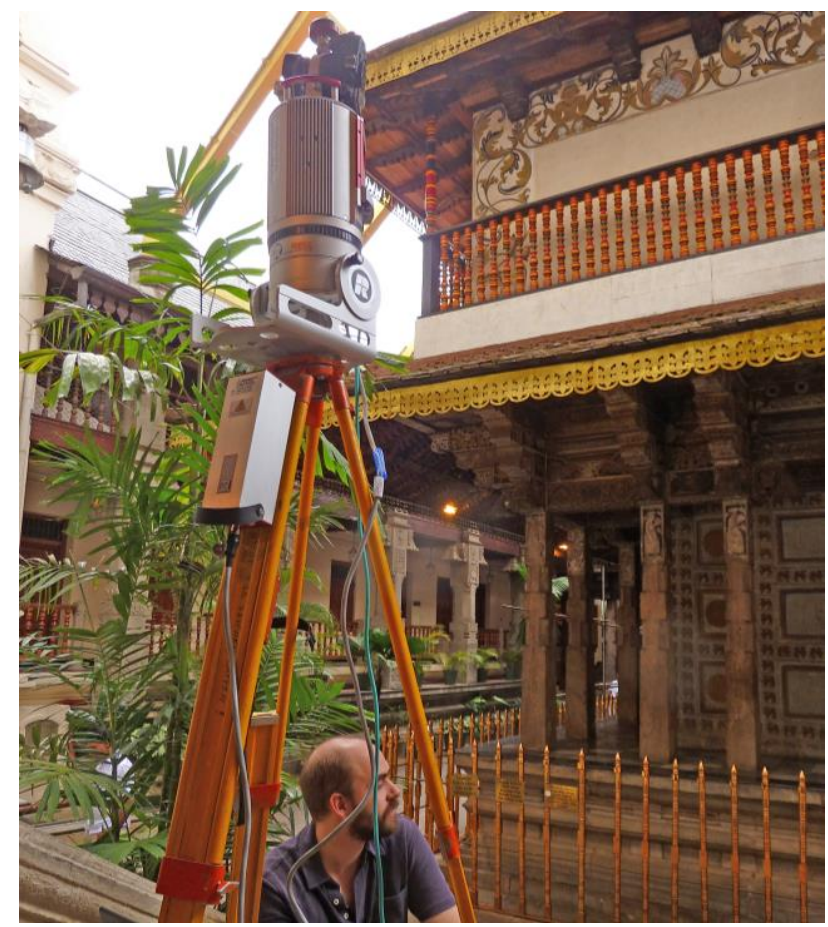

Fig. 3. 3D-Scanning at the shrine with Riegl VZ 400

At each scan position usually two single scans were recorded: first of all a $360^{\circ}$ overview in a resolution between 5 to $15 \mathrm{~mm}$ and a detailed scan of the important areas like façades in a resolution up to 1 to $3 \mathrm{~mm}$ (Fig. 4). Additionally to the documentation of the geometries colour information was recorded for each scan position. Therefore, a Nikon D700 with $14 \mathrm{~mm}$ lens connected to the top of the scanner was used. To achieve a constant colour quality single pictures are captured in manual mode. Quality control and completeness of the pictures were also checked immediately. A much better texture quality is guaranteed by using an external medium format camera with high quality lenses instead of a camera integrated in a scanning device.

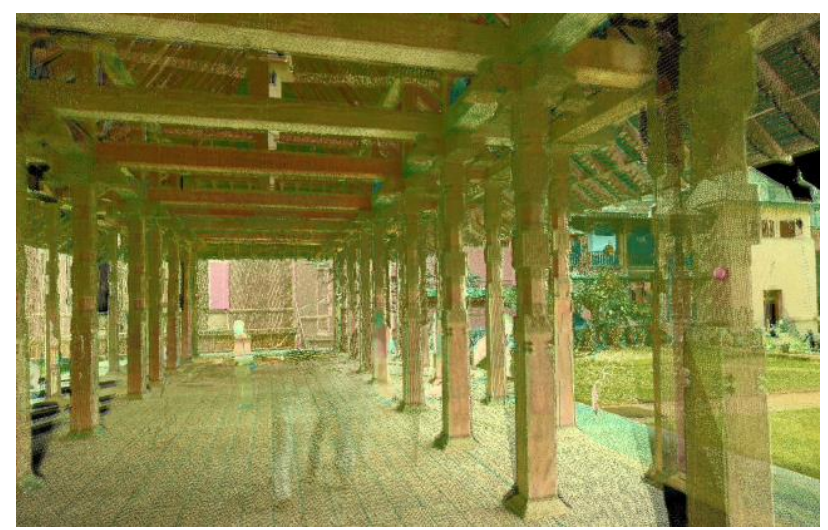

Fig. 4. Point cloud showing the Audience Hall. Combination of reflectance and true colour information 
The measurements were executed in teams of about 4 to 5 persons. At first glance it might look overstaffed but regarding the great importance of the temple in the mind of the local community there was not only a great interest but also worries about the visitors of the temple. Most of the time three colleagues were continuously busy with public relations work. The reactions of the visitors reached from scepticism, fear about the temple up to curiosity and interest in the ongoing documentation. The use of a laptop in the field was also very successful. It was possible to show the perhaps confusing work to the visitors and to explain the work carried out. In the end all visitors who asked about information were convinced and their minds put ease about the work done in the project. There were also many visitors who on top of asking the team doing the measurements went to the Media Office for further information. The requests were so numerous that a live interview at the temples podcast channel was recorded to inform about the project in general and about the harmlessness of the completely non-destructive and contactless work.

During the measuring campaign 189 scan positions were recorded and most of the temple area was scanned. Only some parts like the central areas in front of the shrine and the monks quarters could not be measured yet because of religious concerns. Even the monks were sceptical and bit worried about the modern technologies like the visitors and tourists. After presenting the first project results during the post-processing all concerns could be laid down. In a following project the missing areas could get measured.

\subsection{Documentation of details}

Some surfaces are very richly decorated and documentation in a much higher resolution was necessary. The techniques which could be used for this work were also affected by the projects conditions. Important requirements are (decreasing in weight):

easy handling also during visitor traffic

different light conditions like outdoor and sunlight to diffuse illuminated areas in the inner building parts

controlling of quality and completeness on site

fast data capturing and processing

highest resolution possible

texture information

Image-Based Modelling Techniques were excluded because of the missing possibility for a fast controlling of the completeness, quality, process ability and accuracy on site. The necessary processing time for these purposes would have been too long considering the short time span for the measuring campaign.

High quality SLS like the Aicon/Breuckmann SmartScan or the Zeiss/Steinbichler COMET deliver best results in accuracy and resolution (Bellendorf, 2011). But these techniques have comparatively big sensor heads and periphery devices like the controlling unit requiring more space surround the scanning area which is difficult to use during visitor traffic. It is further possible that visitors could trip over the many cables needed.

All requirements are served by the handheld structured-lightscanner Artec MHT (Fig. 5). The device allows documentation in a resolution up to $0.5 \mathrm{~mm}$ which preserves a really high level of detail. Texture information is captured automatically during scanning. With 15 scans per second the single scans can be matched automatically by a best fit algorithm due to its huge overlapping. To scan an object the device has to be moved in a flowing motion at a distance of about 0.4 to $1.0 \mathrm{~m}$ to the surface which is to be recorded. The scanning process can get checked for completeness directly on site with the controlling laptop. All together the workflow is very intuitive and easy to learn, whereby the instruction of the Sri Lankan colleagues and regular recording of the objects during visitor traffic passed without problems (Fig. 5). In total 11 historical moonstones spread across the whole temple area and parts of the woodcarvings at the Audience Hall were scanned and are ready to be filed in an archive.

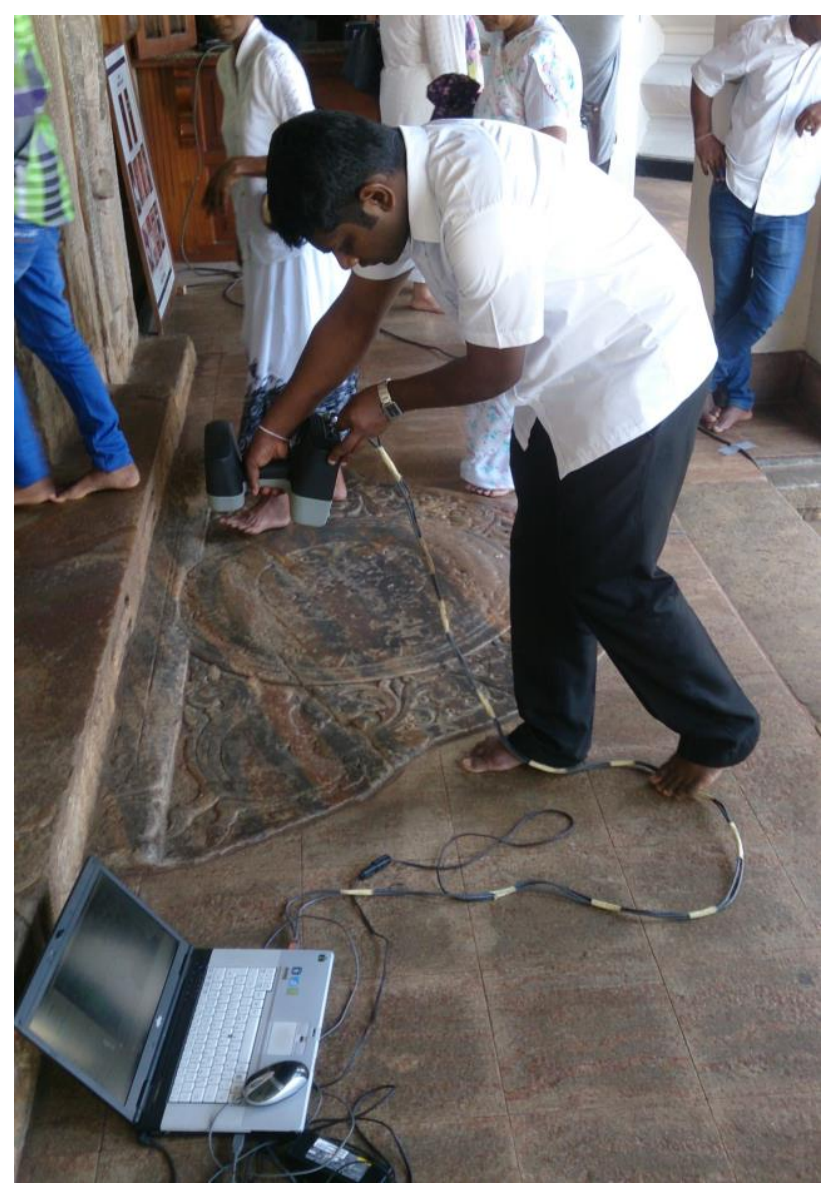

Fig. 5. Documentation of the moonstone at the entrance to the inner temple with Artec MHT

\section{POST-PROCESSING}

\subsection{High resolution 3D-Models of details}

Structured-light-scans were processed to high resolution textured 3D-surface models. After checking the completeness and deleting insufficient scans the batch of single scans was registered and triangulated with the scanning software Artec Studio. In a next step the surface model was exported to Geomagic Studio for further optimizations like reducing of noise and spikes, filling of holes and adjustment of edges and borders. Afterwards the cleaned models were reimported to Artec Studio and became texturized. At the end of the workflow the resulting model was orientated to simplify further processing and exported as *.OBJ-file.

There were two variations of $3 \mathrm{D}$-models processed: One model with highest resolution in the geometry and a second model with reduced geometrical information. Both are connected to colour information by texture mapping. Thus, there is no reduction in quality or resolution of the texture information even for the reduced model. 
The high-resolution-model (Fig. 6) contains all details like cracks, roughness of the surface and delicateness of the ornaments given straight from the geometry. The texture provides additional information about natural grain, colour of the stone, potential paintings and gloss.

The reduced models contain the same texture information but less geometrical details. Because of less detail their data size is much smaller and can easily be used by the Special Projects and Media Bureau for animations and web presentations.

Next to the use for temple purposes the digital models can also be used for example by art historians or archaeologists at Kelaniya University and by the Sri Lankan Department of Archaeology for further research on the moonstones in Kandyan style.

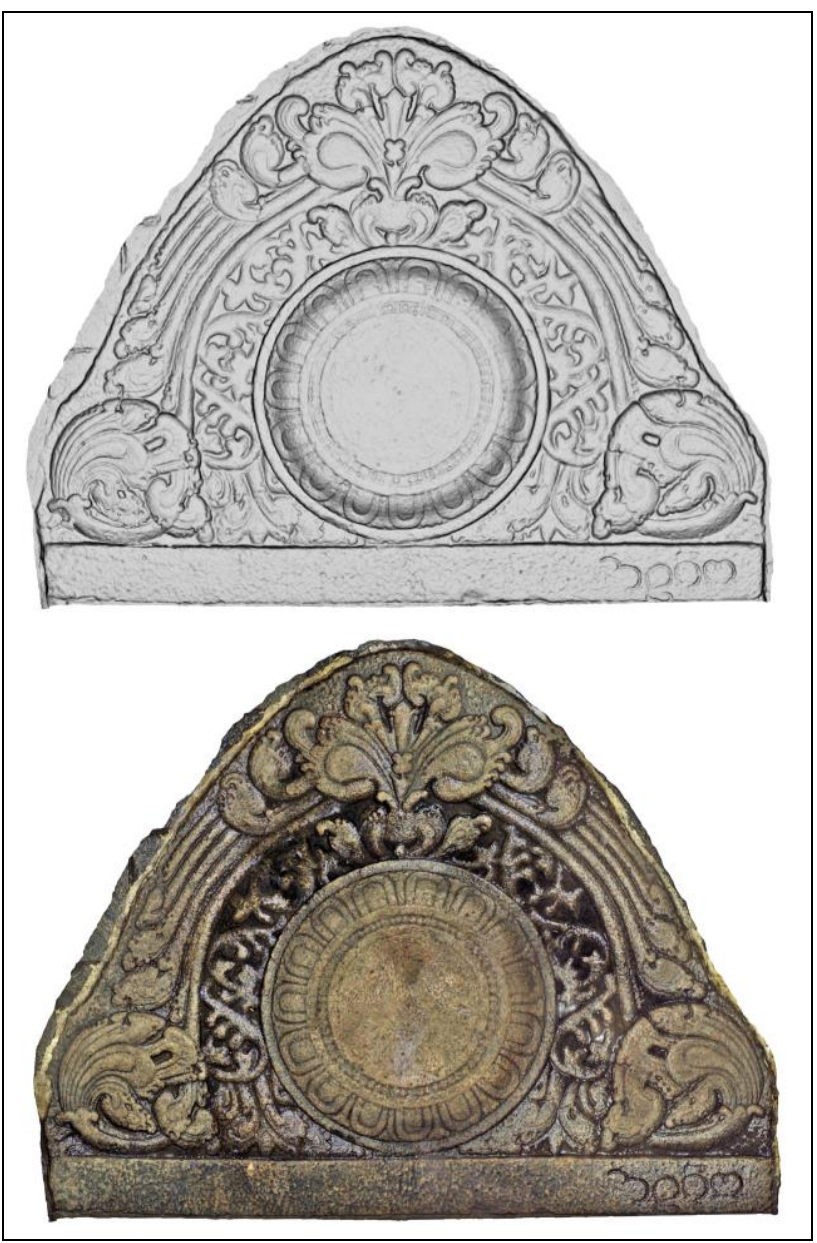

Fig. 6. Moonstone. Shaded relief and textured 3D-Model

\subsection{As-built drawings}

One of the core aims of the use of the TLS-data is generating as-built drawings in CAD. During the project duration it was possible to draw the first three sample plans: a ground floor plan of the entire temple area with park, audience hall and adjoining buildings (Fig. 8), an elevation of the main façade (Fig. 7) and a cross section through the drum beating corridor with view to the main side of the shrine.

For processing the drawings all single scans were first of all matched best-fit with RiSCAN PRO to reduce possible registration errors. Afterwards the scans were separated into bundles and merged to connected point clouds. The separation of the point cloud was done by using building parts like the audience hall, the park, the drum beating corridor or the octagon. AutoCAD was not able to handle one point cloud of the entire scanned area in high resolution so the separation into bundles was necessary to ensure a smooth workflow.

The point clouds of the single bundles were imported to AutoCAD and were processed with the Add-on Pointsense Heritage from Faro/Kubit. The drawing was done by using 3Dpoints. The resolution allows drawings in the level of Detail III and IV by Eckstein (1999) which includes as built drawings in an accuracy up to $0.5 \mathrm{~cm}$ with relevant information about deformation of the structures usable for complicated restorations and construction works.

Drawing the plans ensures a high level of care and experience in point cloud handling (Riedel et al., 2011). The project conditions do not allow later re-measurements of covered areas and there are no useable plan sets existing for controlling or as basis for drawing. The output fulfils the required standards and accuracy. All deformations and wall thicknesses are drawn in good quality and correct scale. The ground floor plan of the whole temple site (Fig. 8) covers an area of more than $160 \mathrm{x}$ $100 \mathrm{~m}$. The plan is drawn in a scale of 1 to 50 . A printout would need a paper size of $3.2 \times 2.2 \mathrm{~m}$ ! During the short project duration there were three plans drawn in quality and scope like this.

Next to the mere documentation of the architectural ensemble there were many other requirements to the drawings in focus of the Special Projects and Media Bureau and the temple administration. The drawings should build a basis for developing emergency escape route maps and visitor guide maps. All data were processed in a way that the additional drawings and the remaining works could be done by the Media Bureau and the Sri Lankan project partners independently.

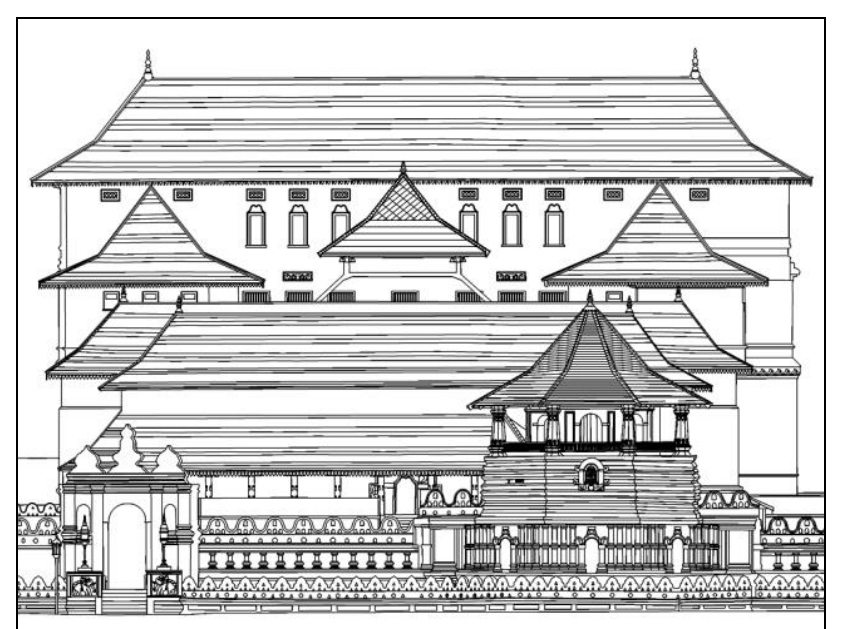

Fig. 7. Elevation of the west façade (detail)

\subsection{Visualisations}

The TLS-data were exported to Autodesk ReCAP and *.lasFiles both containing texture information and can be used as a basis for 3D-visualisations. Furthermore, these files can be used for regular visualisations like camera flights through the point cloud. A first video with a camera flight from the main entrance following the way up to the inner temple and around the shrine (Fig. 9) was done already. The video will expand soon by adding camera flights through the octagon, drumbeating corridor and through the park around the audience hall.

For the animations with more effects and solid surfaces the scan data is the basis for digital rebuilding in correct proportions. Therefore, the textured models of the moonstones can be used, too. 


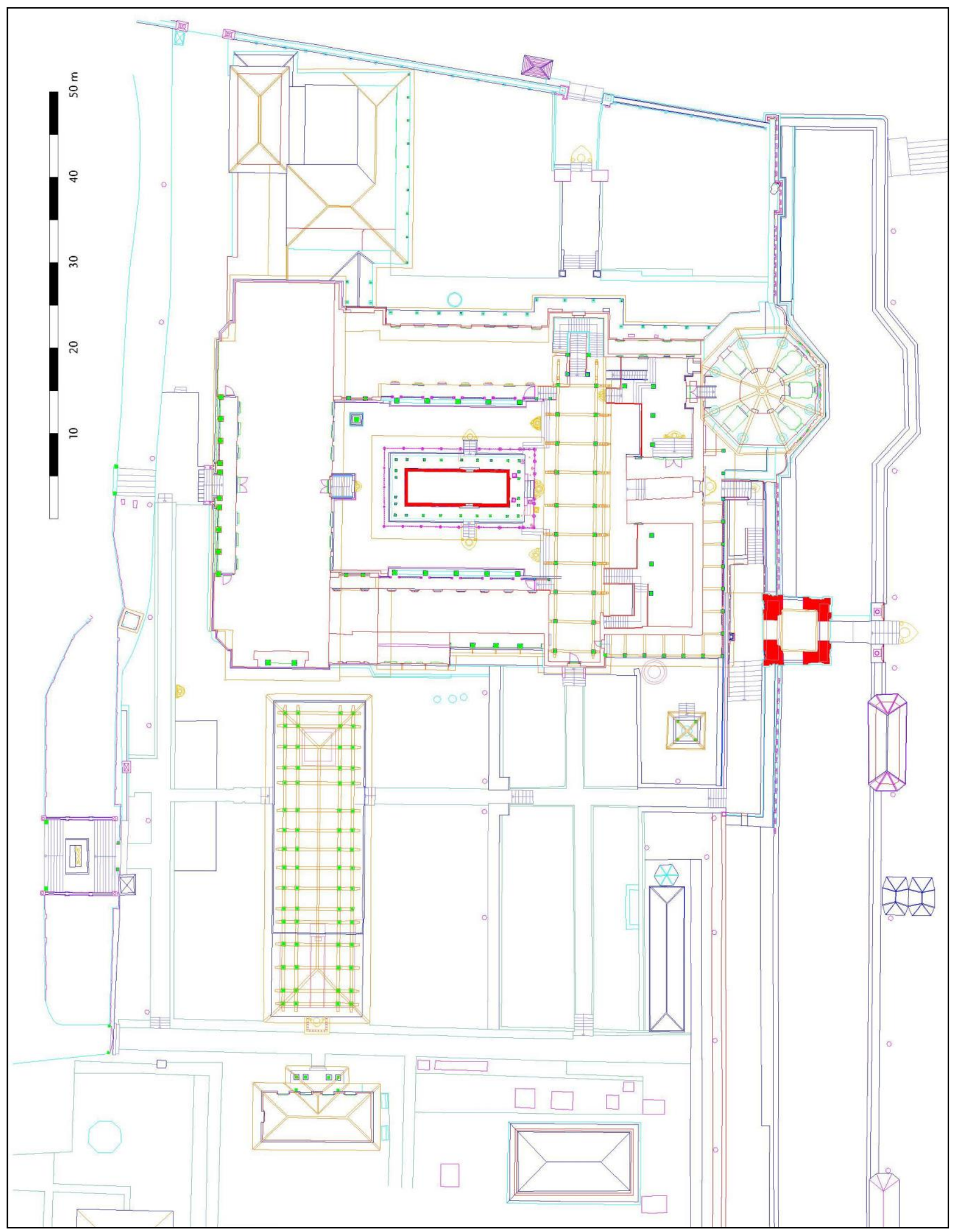

Fig. 8. Sri Dalada Maligawa. Ground floor plan 


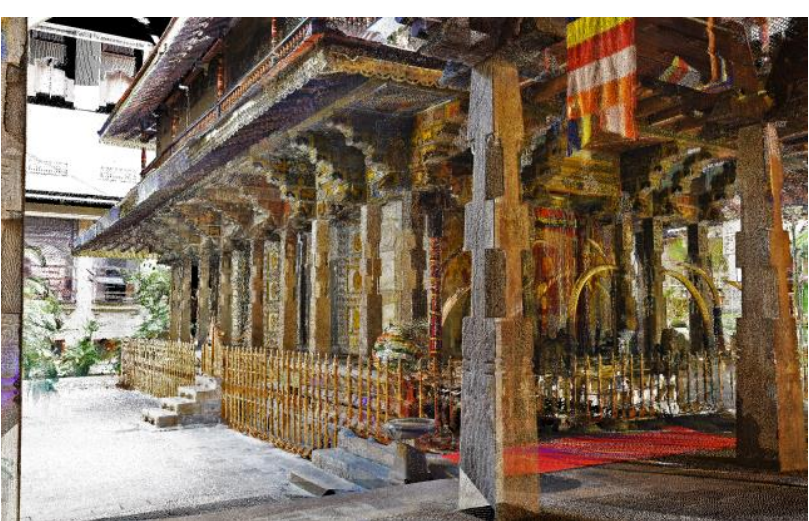

Fig. 9. Point cloud rendering of shrine and courtyard

\section{TRANSFER OF KNOWLEDGE}

Teaching the local specialist staff during the project duration worked well. Especially in the fieldwork the newcomers understand the handling of the techniques immediately and internalised the workflow. After a short time they were able to scan parts of the area on their own without any assistance.

But there were also complications especially during the postprocessing and further analysis. For example, a short travel budget does not allow effective and sufficiently detailed transfer of knowledge over a longer period. Therefore, most of communication has to be done by mail or phone leading to delays or misunderstanding, because of the language barriers. Another unexpected but big problem was the transfer of data between Germany and Sri Lanka. At the end we had to send USB-Sticks by ordinary airmail and had to accept a long delivery time to avoid network administrator restrictions on the one hand and slow, unstable internet connections on the other hand.

\section{OUTLOOK}

Despite limited resources the project has been a success and an important milestone for ongoing preservation of the cultural treasure of the Sri Dalada Maligawa.

The high resolution TLS-data build a basis for comprehensive site monitoring. More CAD-drawings and analysis of the data will be done by the Special Projects and Media Bureau in cooperation with local project partners to complete the documentation of as-build drawings. All following animations, $3 \mathrm{D}$-visualisations and projects will use the recorded scan data. Records of all data are going to be stored and archived at the temple and the involved research institutes.

Processing high quality textured surface models directly basing on the TLS-data will be tested after the project duration. Because of the limited time, the complexity of the geometry and the data size a realisation was not possible during the project. The output would provide much better conditions for further visualisations.

To complete the documentation of missing parts we will look forward to scan these areas in an additional project. There is the need to complete the measuring of some area of the inner temple like the main façade of the shrine, the monks` quarters, the temple administration, the kitchen and the museum. The documentation should also involve the adjacent temples in the west and historical buildings around the area of Sri Dalada.

For a smooth operation of the follow-up projects contact has been established with the University of Kelaniya and the Central Cultural Fund of Sri Lanka. Both institutions are eagerly interested in a cooperation especially for a further transfer of knowledge. In addition, the documentation of the missing parts and the generating of missing CAD-Plans is in the focus of the future cooperation. Therefore, several periodic workshops about handling multiple techniques on site and about processing the data are planned. These workshops will be held in Sri Lanka directly on site at the temple in Kandy and at Kelaniya University as well as at the Centre for Heritage Conservation Studies and Technologies (KDWT) at the University of Bamberg.

During the workshops it is also planned to examine and closely map structural damages at Sri Dalada Maligawa. With a repeated 3D-documentation of endangered surfaces and building parts and a later 3D-comparison of the different campaigns site monitoring will be achieved.

Based on the recently finalized first project and with the encouraging outlook for further projects we hope to be able to contribute greatly to the preservation of this unique interreligious cultural and spiritual centre for future generations.

\section{ACKNOWLEDGEMENTS}

We wish to express our gratitude and appreciation to the German Federal Foreign Office for funding this project as part of the Cultural Preservation Programme. Special thanks and acknowledge is due to the German embassy in Colombo for their great support and also to the other project partners involved like the Media and Special Projects Bureau of Sri Dalada Maligawa, Format4plus GmbH, Infosurv Lanka (Pvt) Ltd and Format4asia (Pvt) Ltd for their invaluable contribution and cooperation throughout the project. At least the authors would like to thank Riegl LMS especially Mr. Andreas Hofstötter for their generous and straightforward support.

\section{REFERENCES}

Bellendorf, P., 2011. Hochaufgelöste 3D-Dokumentation mittelalterlicher Oberflächen. In: Bennewitz, I., Schindler, A., Farbe im Mittelalter. Materialität - Medialität - Semantik. Band I, Berlin.

Coningham, R./Lewer, N., 1999. Paradise Lost: The bombing of the Temple of the Tooth - a UNESCO World Heritage site in Sri Lanka. Antiquity, 73, pp 857-866.

De Silva, T. K. N. P., 1985. Temple of the Tooth, Kandy. Architecture, Sculpture, Painting, Colombo.

De Silva, T. K. N. P., 1994. Kandy - A World Heritage City, Colombo.

Eckstein, G., 1999. Empfehlungen für Baudokumentationen Bauaufnahme - Bauuntersuchung, Stuttgart.

Gonizzi Barsanti, S., Remondino, F., Visintini, D., 2013. 3D Surveying and Modeling of archaeological sites - some critical issues. In: ISPRS Annales of the Photogrammetry, Remote Sensing and Spatial Information Sciences, Strasbourg, France, Vol. II-5/W1, pp 145-150.

Grussenmeyer, P., Landes, T., Doneus, M., Lerma, J.L., 2016. Basics of Range-Based Modelling Techniques in Cultural Heritage 3D-Recording. In: Stylianidis, E., Remondino, F., 3D Recording, Documentation and Management of Cultural Heritage, Dunbeath. 
IBM, 2015. Exhibition of the International Buddhist Museum (IBM) at Kandy, Sri Lanka.

Riedel, A., Henze, F., Marbs, A., 2011. Paradigmenwechsel in der historischen Bauforschung? Ansätze für eine effektive Nutzung von 3D-Informationen. In: Heine, K., Rheidt, K., Henze, F., Riedel, A., Von Handaufmass bis High Tech III. 3D in der historischen Bauforschung, Darmstadt/Mainz.

Seneviratna, A., 1987. The Temple of the Sacred Tooth Relic An Architectural History of the Dalada Maligawa - The Symbol of the Buddhist Faith and Sovereignty in Sri Lanka, Colombo.

Stylianidis, E., Georgopoulos, A., Remondino, F., 2016. Basics of Image-Based Modelling Techniques in Cultural Heritage 3D Recording. In: Stylianidis, E., Remondino, F., 3D Recording, Documentation and Management of Cultural Heritage, Dunbeath.

Wiedemann, A., 2004. Handbuch Bauwerksvermessung. Geodäsie - Photogrammetrie - Laserscanning, Basel. 